\title{
2007 Pisacano Scholars
}

The Pisacano Leadership Foundation, the philanthropic arm of the American Board of Family Medicine (ABFM), recently selected its 2007 Pisacano Scholars. These 5 medical students follow in the footsteps of 61 scholar alumni who are practicing physicians and 15 current scholars who are enrolled in family medicine residency programs across the country. The Pisacano Leadership Foundation was created in 1990 by the ABFM in tribute to its founder and first executive director, Nicholas J. Pisacano, MD (1924-1990). Each Pisacano Scholar has demonstrated the highest level of leadership, academic achievement, communication skills, community service, and character and integrity.

Rachel Summer Claire Friedman, a 2007 Pisacano Scholar, is a 4th-year medical student at Yale School of Medicine. She graduated magna cum laude from Harvard University with a Bachelor of Arts in History of Science. She was also elected to Phi Beta Kappa. In addition, Rachel received a University Health Services Acknowledgment award for cofounding and directing the Harvard Community Health Initiative, a peer educational program. She also planned the first Harvard-MIT Conference on Alternative Medicine during her freshman year, and for 3 years she tutored 1 st and 2 nd grade students in nearby public schools with the Harvard HAND AmericaReads Program.

After graduation, Rachel worked for 2 years as a founding faculty member of the American Hebrew Academy, a Jewish boarding school in North Carolina. As assistant dean of student life, she created weekly Jewish and social programming for 75 high school students. Rachel founded and directed the a cappella group, running club, student/faculty book club, and a healthy living club.

Rachel has continued her academic excellence and community involvement throughout medical school as well. Earlier this year, she was selected by the medical school deans as one of 2 medical student representatives for the Yale delegation trip to China, which was organized at the invitation of the Chinese government and President $\mathrm{Hu}$ Jintao.

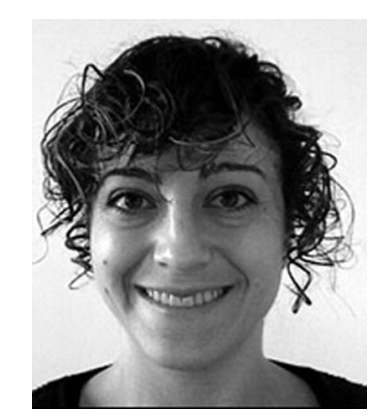

Rachel Summer Claire Friedman

During her second year of medical school, Rachel was one of 8 medical students selected nationally to participate in an 8-week internship with the American Society for Clinical Nutrition. She has taught Dr. David L. Katz's Nutrition Detectives curriculum to over 600 schoolchildren in Connecticut and is the founder of the Yale Nutrition Detectives program. She is also the coauthor on Dr. Katz's upcoming 2 nd edition of his textbook Nutrition in Clinical Practice.

As the national student director of the American Medical Student Association Foundation Education Development in Complementary and Alternative Medicine (EDCAM) Project Grant, Rachel planned the 3rd Annual Complementary and Alternative Medicine Leadership Training Program for medical students. Rachel has also been instrumental in the establishment of an interdisciplinary center for integrative medicine at Yale. This past year, she received a research fellowship and also completed the requirements for a master's degree in health science.

After residency, Rachel envisions developing a holistic family practice that uses creativity and innovation to provide maximum support and care for patients both during and beyond office visits. Some of her ideas include group visits, yoga and cooking classes, mind-body training, and providing healthy food samples and sample workouts for her patients.

Derek Jackson, a 2007 Pisacano Scholar, is a 4th-year medical student at the University of Washington School of Medicine (UW). Derek 


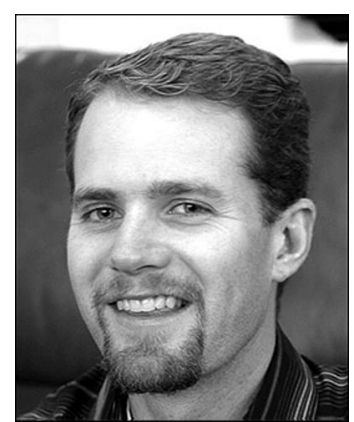

Derek Jackson

graduated with honors from Stanford University with a Bachelor of Arts in Latin American Studies. Derek received the Creativity in Latin American Studies Award his senior year, which is given to the graduating student exhibiting the most innovative approach to his/her education with respect to course work, research, and study abroad. Derek's passion for the Latino community began as a child when he worked alongside immigrant workers on his parent's dairy farm in southern Idaho. Since that time Derek has served in many capacities in the Latino community. He spent 2 months in Peru and another 2 months in Mexico teaching English to Spanish-speaking natives. He also completed an internship at a hospital in Peru and then served as a volunteer migrant outreach care coordinator in rural Idaho during a year away from his undergraduate education.

As a medical student, Derek has continued his involvement with the Latino community. During his first year of medical school, he began implementing a project that would provide information to Latino men in Idaho about sexual safety and would assess which risk-taking practices needed to be addressed by local outreach programs. He has since presented his results to fellow students at UW, at the Western Student Medical Research Forum Conference in 2006, and to physicians and social workers in Idaho. $\mathrm{He}$ is now preparing to submit his research for publication. During his second year of medical school, Derek completed a clerkship at a hospital in Guanajuato, Mexico. He was the first student sent by the University of Washington to what is now an established program between the state of Guanajuato's medical school and the UW School of Medicine.

Upon completion of residency, Derek would like to return to Idaho and hopes to serve the diverse group of immigrants and rural populations

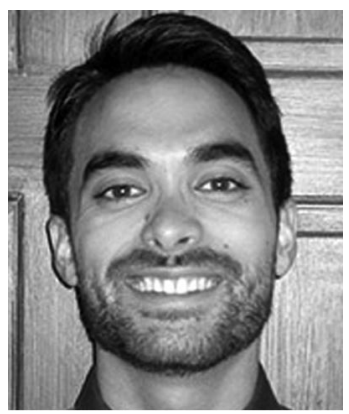

Brian "Yoshi" Laing

in his home state. He doesn't see his future in medicine as a job or career but as a lifestyle choice based on passion and the opportunity to leave things better than he has found them.

Brian "Yoshi" Laing, a 2007 Pisacano Scholar, is a 4th-year medical student at the University of California-San Francisco School of Medicine (UCSF). Yoshi graduated with honors from Stanford University with a Bachelor of Science in Biological Sciences. He also received a number of awards and scholarships, including the Stanford Asian American Community Award/Scholarship for Community Building. Yoshi also led 12 participants in a winter course on health policy and disparities in health care. They traveled to the California State capitol and to health care sites in the rural central valley.

As a medical student, Yoshi has continued his academic excellence and community service. $\mathrm{He}$ volunteered for 2 years with the student homeless clinic, performing histories and physical exams. For the past year, Yoshi has served as a clinical volunteer with the Mission Neighborhood Health Center, which mainly serves recent Latino immigrants. Yoshi has also served as student chair of UCSF's Family Medicine Interest Group and as coordinator for a Social Activism elective and a Health Policy elective. He helped found the UCSF Health Disparities Working Group to develop medical school curricula on health disparities and presented a poster on the working group at several conferences. During his second year, Yoshi was copresident of UCSF's American Medical Student Association chapter, which hosted the annual west coast conference. In his second year he also volunteered as a student coordinator for Physicians for a Democratic Majority, a committee dedicated to campaigning for candidates who will work toward universal health care. 
Yoshi is currently spending a year on staff with the UCSF Center for Excellence in Primary Care (CEPC), working on primary care redesign and health policy. Yoshi was selected as the sole medical student presenter at the CEPC's inaugural conference last year. He also serves as a reviewer for Primary Care E-Letter, a publication of the CEPC. Earlier this year, Yoshi spent a month interning at the Graham Center in Washington, DC, studying the politics of physician payment policy.

After learning Kenpo Karate and Tae Know Do as a child, several years ago Yoshi began learning Capoeira, a dance-like Afro-Brazilian martial art. He founded the Stanford Capoeira Group and continues to train and perform with Capoeira USA in San Francisco. He also enjoys playing the saxophone and has performed at several school functions along with 3 fellow classmates. After residency, Yoshi hopes to serve as both a clinician and health care advocate for underserved populations.

Amy McIntyre, a 2007 Pisacano Scholar, is a 4th-year medical student at the Warren Alpert Medical School of Brown University. She was recently accepted to the MPH program at the Harvard School of Public Health and will be completing a 9-month program in the Family and Community Health Track. Amy graduated summa cum laude from Providence College with a Bachelor of Arts in Chemistry and Biology. She received a number of scholarships at Providence, including the Presidential Scholarship, a full-tuition merit scholarship, and she was a member of Alpha Epsilon Delta, a national premedical honor society. Amy was also involved in many community service activities. She volunteered with Habitat for $\mathrm{Hu}-$ manity and worked with homeless individuals through the social services office at Amos House.

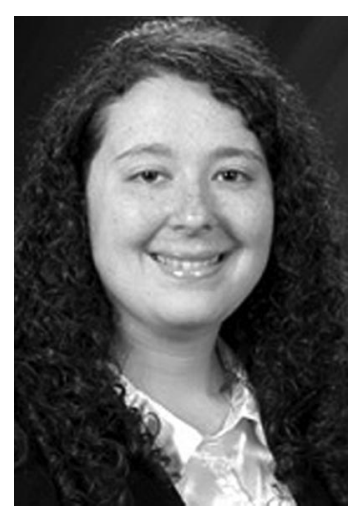

Amy McIntyre
Amy worked for 2 years as a research assistant with the Department of Chemistry and Biochemistry at Providence and ultimately made a poster presentation at the 2003 National Meeting of the American Chemical Society.

Amy has continued her academic excellence and community involvement throughout medical school. She has received several awards and scholarships including a National Health Service Corps Scholarship. She also received a scholarship from the Betty Ford Summer Institute for Medical Students to observe its inpatient program and to attend educational workshops. Amy has volunteered with a community health clinic performing screening and physicals for homeless patients, and more recently with a health center performing community diabetes screenings. She has spent 2 summers interning with the Rhode Island SEARCH Program (Student Experiences \& Rotations in Community Health) of the National Health Service Corps. Since beginning medical school, Amy has also been involved with and held many positions with the American Academy of Family Physicians (AAFP), the Rhode Island Academy of Family Physicians (RIAFP), and the American Medical Student Association. She currently serves as the National Family Medicine Interest Group (FMIG) Coordinator for the AAFP and the Student Liaison to the RIAFP Executive Board. Just recently, Amy was elected as the 2008 Student Chair of the AAFP's National Conference.

Amy envisions herself practicing the full scope of family medicine in a community health center, where she will be able to practice communityoriented primary care. She hopes to engage the community and facilitate its involvement in improving health delivery and outcomes, and to address the biological, social and psychological factors that create health disparities for individual patients and the population as a whole.

David O'Gurek, a 2007 Pisacano Scholar, is a 4th-year medical student at Penn State College of Medicine. He graduated summa cum laude from St. Joseph's University (Philadelphia, PA) with a Bachelor of Science in Biology. He was inducted into Phi Beta Kappa as a junior and was a member of the Dean's list all 4 years at St. Joseph's. David was also a member of Alpha Epsilon Delta, a national premedical honor society, Alpha Sigma $\mathrm{Nu}$, a national Jesuit honor society, and Sigma Xi, a national scientific research honor society. As an undergradu- 


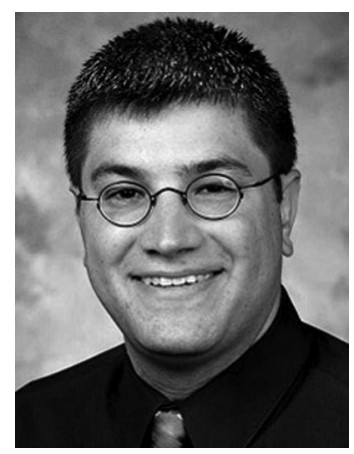

David 0'Gurek

ate, David gained a great deal of experience in the medical field-shadowing in a private practice, volunteering in an emergency department, spending a summer doing research as part of an ongoing 3 -year project, and working as a laboratory teacher's assistant for biology, genetics, histology, and physiology courses. David has also been actively involved in community service through campus ministry at St. Joseph's and as a dedicated volunteer since childhood at his hometown church and in his local community.

As a medical student David has continued his academic excellence, receiving a number of scholarships and awards. Last year he was recognized by the Pathology Honor Society, a medical student society honoring only the highest-achieving medical students. David has volunteered with the Penn State College of Medicine Family Practice Interest Group (FPIG) in various roles since his first year of medical school. He recently served with the Advance Directive Project, a project that had been inactive for quite some time because of lack of student interest. As a result of David's efforts and leadership, the FPIG board was able to reach 100 members of the local community through several seminars informing them of the importance of planning end-of-life care. David has also volunteered his time at the Bethesda Mission/LionCare Clinic, a student-run free clinic in downtown Harrisburg that serves the homeless and uninsured. In addition, David is a member of the Government and Legal Affairs Commission of the Pennsylvania Academy of Family Physicians, a member of the Catholic Medical Organization with his school, and a member of the Rural and Underserved Medicine Group.

David plans to return to his hometown, Summit Hill, a close-knit community in the mountains of Pennsylvania, to practice. He also hopes to remain actively involved both at the state and national level, serve as a preceptor and mentor to medical students, and perhaps become more actively involved in academic medicine. 